\title{
PATH ERRORS IN SUGARCANE TRANSSHIPMENT TRAILERS
}

\author{
Bruna P. Passalaqua ${ }^{1 *}$, José P. Molin $^{1}$ \\ ${ }^{1 *}$ Corresponding author. University of São Paulo, "Luiz de Queiroz" College of Agriculture, Department of \\ Biosystems Engineering, Laboratory of Precision Agriculture/ Piracicaba - SP, Brazil. \\ E-mail: bruna.passalaqua@gmail.com | ORCID ID: https://orcid.org/0000-0001-5168-0059
}

\section{KEYWORDS}

lateral slope, automatic steering, traffic control.

\begin{abstract}
The need for accuracy in sugarcane machine traffic has boosted the adoption of automatic steering systems. These have been used in tractors pulling transhipment trailers. Such sets are long and articulated, which hinders their performance and benefits due to alignments in curved and laterally sloped paths. In this sense, this study aimed to quantify shifts in direction to which tractors and transshipment trailers are subjected while traveling straight and curved paths on different terrain slopes. We evaluated an internal transport system composed of one tractor and two three-axle transshipment trailers, equipped with GNSS receivers and RTK correction system, for their respective positioning. Pass-to-pass errors were evaluated by differences in orthogonal distance between antenna positioning and a reference line. Results showed that misalignment errors of tractor and trailer sets are strongly associated with path type and terrain lateral slope, besides being increasingly affected between set parts. Trailer path errors were above acceptable limits, thereby complementary solutions are needed regarding tractor automatic steering.
\end{abstract}

\section{INTRODUCTION}

Agricultural mechanization has been an essential technological advance, and its use in sugarcane crops has promoted system gains, mainly in terms of labor efficiency. But, intense vehicle traffic in crop areas causes some problems such as soil compaction and sugarcane ratoon damages.

In sugarcane farming systems, machine traffic must be avoided to ensure physiological completeness of plant regrowth and respective yields (Paula \& Molin, 2013). Therefore, when traveling over newly harvested areas, machinery wheels must follow crop rows straightly. However, such process is increasingly challenging given its restricted margin of allowed misalignment to prevent root system damages (Spekken et al., 2014). Such a gap can be estimated by distance between the end of wheelset and the beginning of crop development area but changing according to equipment size.

The need for accuracy in machine traffic encouraged the use of technologies to optimize displacements of mechanized sets in sugarcane fields. In parallel, steering systems, automatic steering, and robotics have been developed and evolved, thus a greater effort has been directed to route planning (Spekken et al., 2016). For tractors used in planting and for combine harvesters, automatic steering systems have already been used. In turn, for tractors with transshipment trailers, such feature, when adopted, makes use of technology with less positioning accuracy. Sets formed by a tractor pulling one or two transshipment trailers are long and articulated, which makes automatic steering performance questionable as it acts only on the tractor.

Terrain slope is a limiting factor for mechanization as gradients above $12 \%$ restrict the movement of agricultural machinery in sugarcane production fields. Performance of automatic steering is associated with transverse errors to the path. These can be attributed to vehicle dynamics, positioning error, machine type, operating environment, GNSS signal quality, among others (Easterly et al., 2010).

Given the above, this study aimed to quantify shifts in direction to which tractors and transhipment trailers are subjected during straight and curved paths on terrains of different slopes. Such shifts were obtained for each part of the set and under real field conditions.

\footnotetext{
${ }^{1}$ University of São Paulo, "Luiz de Queiroz" College of Agriculture, Department of Biosystems Engineering, Laboratory of Precision Agriculture/ Piracicaba - SP, Brazil.
}

Area Editor: Fabio Henrique Rojo Baio

Received in: 11-20-2018

Accepted in: 3-5-2020 


\section{MATERIAL AND METHODS}

In this study, three experiments were carried out in a sugarcane producing field, located in western São Paulo State $\left(20^{\circ} 45^{\prime} 20^{\prime \prime} \mathrm{S}\right.$ latitude and $50^{\circ} 34^{\prime} 08^{\prime \prime} \mathrm{W}$ longitude). To this end, three first cut areas were chosen (Table 1), where planting was done in simple rows spaced $1.50 \mathrm{~m}$ apart, and different slopes and paths were evaluated. The planting rows were previously designed from a topographic and planimetric survey of the terrain. Combine harvesters were operated by an activated automatic steering system, and the operators of tractors pulling transshipment trailers were maintained throughout the entire evaluation time. The first experiment aimed to assess manual steering as a function of relief and path type (curved or straight). The second and third experiments, in straight paths, evaluated steering type effect on increasing slope terrains.

TABLE 1. Characterization of the study areas.

\begin{tabular}{|c|c|c|c|c|c|c|c|c|}
\hline & \multicolumn{3}{|c|}{ Experiment 1} & \multicolumn{2}{|c|}{ Experiment 2} & \multicolumn{3}{|c|}{ Experiment 3} \\
\hline & A 1.1 & A 1.2 & A 1.3 & A 2.1 & A 2.2 & A 3.1 & A 3.2 & A 3.3 \\
\hline Path & Straight & Straight & Curved & Straight & Straight & Straight & Straight & Straight \\
\hline Average slope (\%) & 2 & 9 & 9 & 1 & 2 & 5 & 7 & 8 \\
\hline Automatic steering & \multicolumn{3}{|c|}{ No } & \multicolumn{2}{|c|}{ Yes/ No } & \multicolumn{3}{|c|}{ Yes/ No } \\
\hline Average yield $\left(\mathrm{Mg} \mathrm{ha}^{-1}\right)$ & \multicolumn{3}{|c|}{132} & \multicolumn{2}{|c|}{121} & \multicolumn{3}{|c|}{109} \\
\hline
\end{tabular}

Data were collected using a 4x2 FWD tractor (6180J model, John Deere, Montenegro, Brasil), with a rated power of $132 \mathrm{~kW}$. It was equipped with an AutoPilot automatic steering system (Trimble, Sunnyvale, CA, USA) and a GNSS receiver (Global Navigation Satellite Systems), with an AgGPS 262 GPS receiver, AgGPS NavController II controller (Trimble, Sunnyvale, USA), and an RTK correction system. The tractor pulled two threeaxle transshipment trailers (TAC 14000 model, Civemasa, Matão, Brazil), with a $14 \mathrm{Mg}$ load capacity each.

To record path data, both trailers were equipped with GNSS receivers with RTK signal correction and a computer. The first trailer had an FMX receiver (Trimble,
Sunnyvale, USA), while the second an X30 one (Topcon, Tokyo, Japan), working at a frequency of $0.5 \mathrm{~Hz}$ (Figure 1). Antennas were positioned at the rear of both trailers, and their coordinates were properly transferred to the center of the last wheelset. A GNSS antenna, which was used as a signal base, was positioned within a $2-\mathrm{km}$ radius of each area, and all data loggers received signals therefrom.

The average speed of the set (harvester and transhipment trailer) during the operation was $1.25 \mathrm{~m} \mathrm{~s}^{-1}$ $\left(4.5 \mathrm{~km} \mathrm{~h}^{-1}\right)$. To avoid reductions in harvest operational efficiency, the equipped set was not only attached to one combine harvester, which allowed data logging throughout the area continuously.

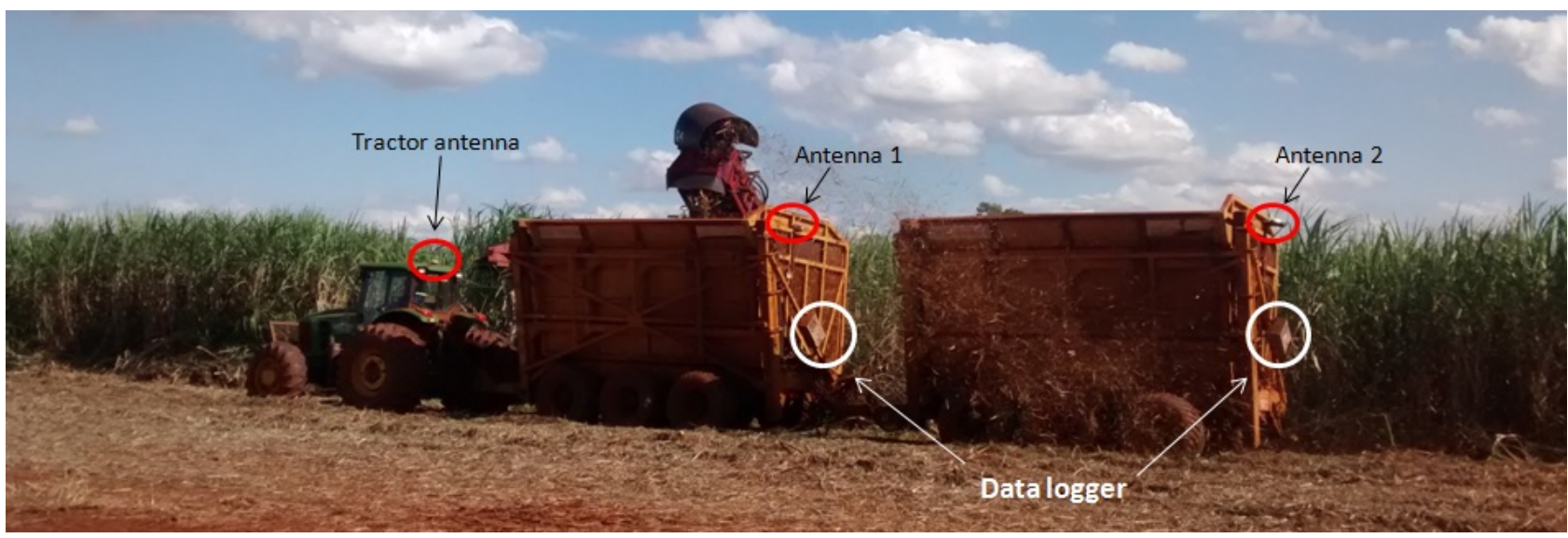

FIGURE 1. Arrangement of GNSS antennas and data loggers in the set.

Data export, organization, and analyses were performed through AutoCAD (Autodesk, San Rafael, USA) and QGIS (Open Source Geospatial Foundation, Beaverton, USA) software. Pass-to-pass errors were evaluated by the difference of the orthogonal distance between the positioning of the antennas, in the center of the tractor and of each trailer, and a reference line. To this end, we used an algorithm developed by Spekken et al. (2014), which compares displacement between two sequences of line segments. The minimum distance of these two distance pairs determines the shift in travel direction from the reference point (Molin et al., 2011; Spekken et al., 2014). As data collection was according to the availability of the equipped set in the areas, a minimum collection time was established so that a minimum of 400 data could be collected in each tested condition. Errors were analyzed using descriptive statistics, obtaining mean error, median, and standard deviation, in addition to the value of $95 \%$ probability of occurrence $(2 \sigma)$, which is normally used as the main metric in studies of this nature (Rounsaville et al., 2016). These were determined for all components of the set (tractor and third axle of each transhipment trailer). These errors were confronted with a safety clearance criterion (Belardo et al., 2015), established by the studied sugarcane plant, which is $0.10 \mathrm{~m}$. 


\section{RESULTS AND DISCUSSION}

Allied to the proposed method, set instrumentation and data collection system were effective in quantifying shifts in direction. But, for broader modeling under different scenarios, data should be collected in the entire area. This means instrumenting several transshipment sets or even dedicating a single combine harvester for harvest data collection.

The first experiment considered only manual steering and was based on near-flat and little-sloped terrains, as well as straight and curved paths. If compared to the path projected in A1.1, for example, the alignment errors in the tractor front axle resulted in $2 \sigma$ values of 0.09 $\mathrm{m}$ above the acceptable limit (Table 2).

TABLE 2. Pass-to-pass errors of the tractor and third axle of transshipment trailers in each area and with manual steering in experiment 1 .

\begin{tabular}{|c|c|c|c|}
\hline \multicolumn{4}{|c|}{ A1.1 (average slope $2 \%$ / straight path) } \\
\hline & Tractor & Trailer 1 & Trailer 2 \\
\hline $\mathrm{N}$ & 817 & 817 & 817 \\
\hline Minimum error (m) & 0.001 & 0.001 & 0.001 \\
\hline Maximum error (m) & 0.177 & 0.484 & 0.590 \\
\hline Average error (m) & 0.083 & 0.109 & 0.129 \\
\hline $\mathrm{CV}(\%)$ & 114.4 & 122.0 & 126.3 \\
\hline$\sigma(\mathrm{m})$ & 0.095 & 0.133 & 0.163 \\
\hline $2 \sigma(\mathrm{m})$ & 0.190 & 0.266 & 0.326 \\
\hline \multicolumn{4}{|c|}{ A1.2 (average slope 9\% / straight path) } \\
\hline $\mathrm{N}$ & 1257 & 1257 & 1257 \\
\hline Minimum error (m) & 0.002 & 0.001 & 0.002 \\
\hline Maximum error (m) & 0.699 & 0.997 & 1.330 \\
\hline Average error (m) & 0.426 & 0.473 & 0.521 \\
\hline $\mathrm{CV}(\%)$ & 90.8 & 99.5 & 113.0 \\
\hline$\sigma(\mathrm{m})$ & 0.338 & 0.421 & 0.454 \\
\hline $2 \sigma(\mathrm{m})$ & 0.674 & 0.842 & 0.908 \\
\hline \multicolumn{4}{|c|}{ A1.3 (average slope 9\% / curved path) } \\
\hline $\mathrm{N}$ & 2013 & 2013 & 2013 \\
\hline Minimum error (m) & 0.054 & 0.001 & 0.001 \\
\hline Maximum error (m) & 1.49 & 1.483 & 1.496 \\
\hline Average error (m) & 0.447 & 0.533 & 0.549 \\
\hline $\mathrm{CV}(\%)$ & 102.6 & 106.0 & 114.2 \\
\hline$\sigma(\mathrm{m})$ & 0.409 & 0.525 & 0.607 \\
\hline $2 \sigma(\mathrm{m})$ & 0.818 & 1.050 & 1.214 \\
\hline
\end{tabular}

$\mathrm{N}$ : Number of sampling points; CV (\%): Coefficient of variation; $\sigma$ : Standard deviation; $2 \sigma: 95 \%$ error probability

Misalignment errors increase with changes in relief (A1.2) and path (A1.3), reaching respective increases of 6.74 and 8.18 times above the acceptable level of $0.10 \mathrm{~m}$. In straight paths, the last axle of the second trailer misaligned in $0.326 \mathrm{~m}$, with an average lateral slope of $2 \%$, increasing to $0.908 \mathrm{~m}$ in straight path and $9 \%$ slope, and $1.214 \mathrm{~m}$ in a curved path. Such errors were 12 times more than acceptable. Within this error range, the last axis of the second trailer passed over the adjacent crop row.

Moreover, when path type and relief changed (Figure 2), some one-off and trend alterations in path error between both set components were observed. These are probably due to sudden shifts in lateral slope throughout the path. It points to a need for data collection in the total area so that the effect of lateral slope on lateral deviations could be thoroughly detailed. 
Area 1.1

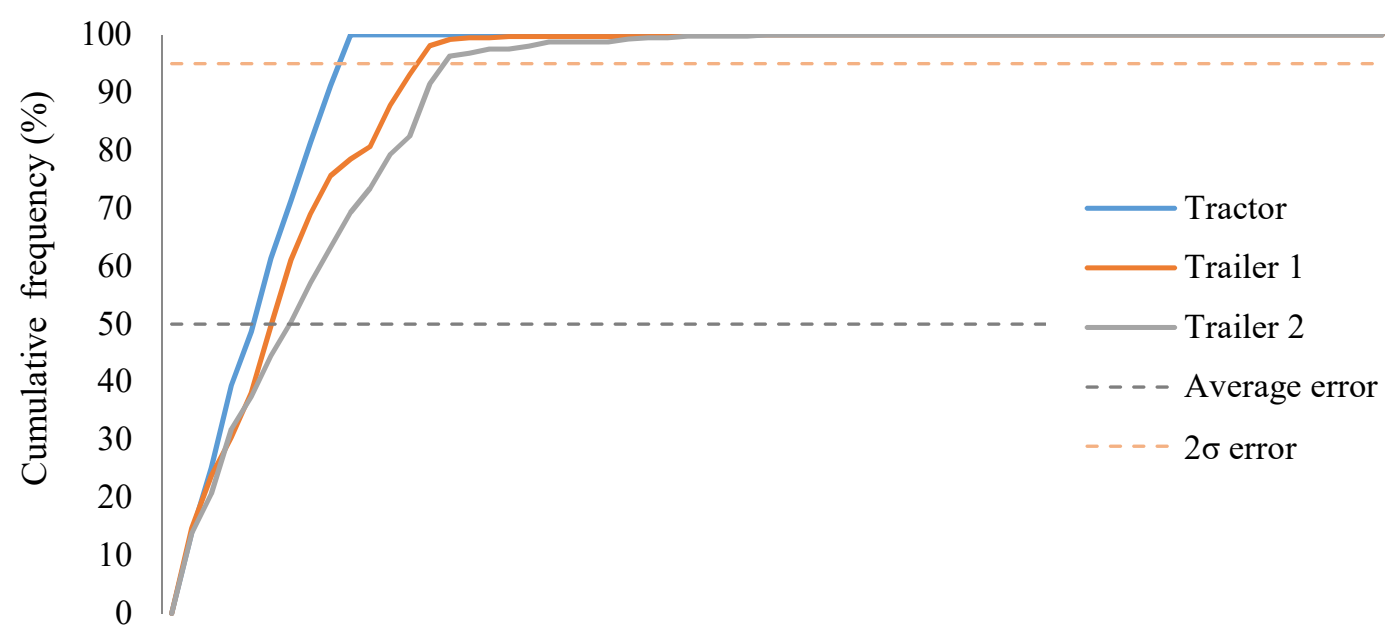

Area 1.2

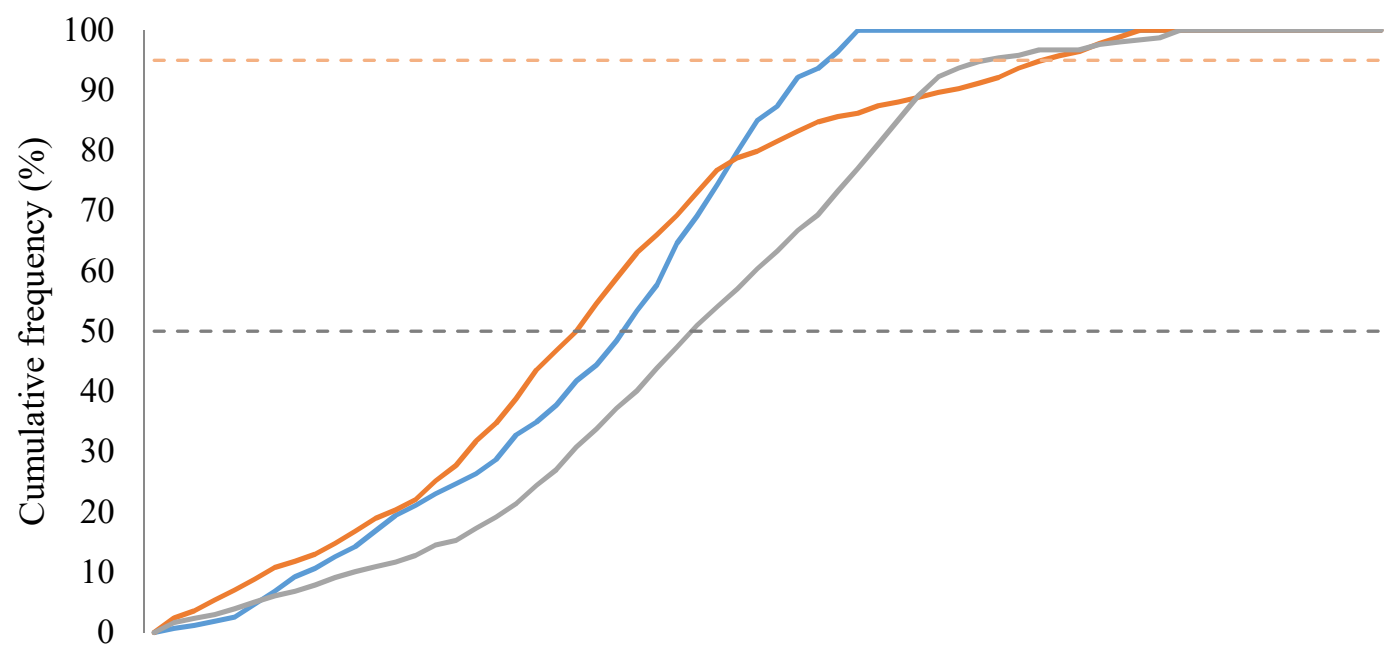

Area 1.3

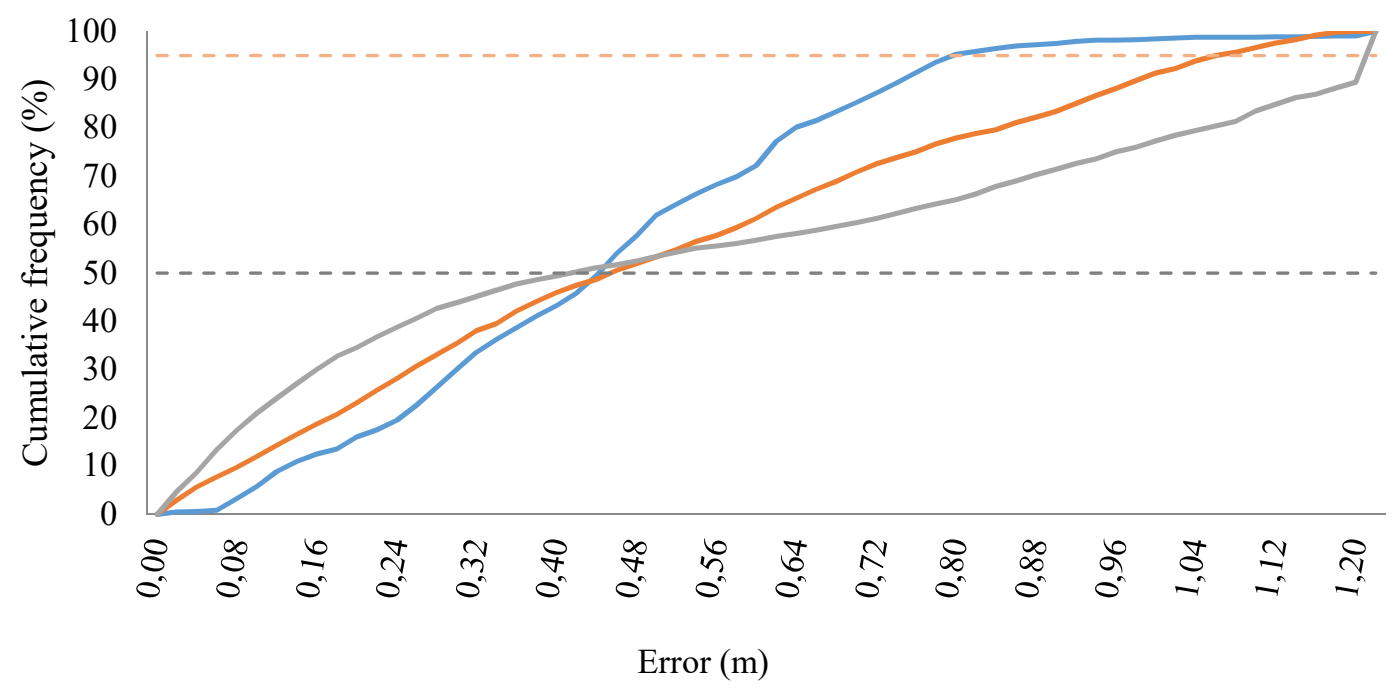

FIGURE 2. Cumulative frequency (probability) of errors per part of the set in near-flat terrains and straight paths (A1.1), steepslope terrains and straight paths (A1.2), steep-slope terrains and curved paths (A1.3).

The second experiment compared manual and automatic steering in a near-flat terrain, assessing direction shifts of the set, with a minimal lateral thrust effect from the cross-sectional slope. Table 3 presents the descriptive statistics of misalignment errors in each area: terrains with average slopes of $1 \%$ (A 2.1) and 2\% (A 2.2). 
TABLE 3. Pass-to-pass errors of each set part (tractor and transhipment trailers) in areas with little slope (experiment 2) and automatic and manual steering.

\begin{tabular}{|c|c|c|c|c|c|c|}
\hline \multicolumn{7}{|c|}{ A 2.1 (average slope $1 \%$ ) } \\
\hline & \multicolumn{3}{|c|}{ Automatic steering } & \multicolumn{3}{|c|}{ Manual steering } \\
\hline & Tractor & Trailer 1 & Trailer 2 & Tractor & Trailer 1 & Trailer 2 \\
\hline $\mathrm{N}$ & 2311 & 2311 & 2311 & 2570 & 2570 & 2570 \\
\hline Minimum error (m) & 0.000 & 0.000 & 0.000 & 0.000 & 0.000 & 0.000 \\
\hline Maximum error (m) & 0.148 & 0.223 & 0.331 & 0.256 & 0.377 & 0.634 \\
\hline Average error (m) & 0.019 & 0.086 & 0.108 & 0.113 & 0.133 & 0.159 \\
\hline CV $(\%)$ & 163.1 & 115.1 & 123.1 & 98.2 & 142.1 & 153.4 \\
\hline$\sigma(\mathrm{m})$ & 0.031 & 0.099 & 0.133 & 0.111 & 0.189 & 0.244 \\
\hline $2 \sigma(\mathrm{m})$ & 0.062 & 0.198 & 0.266 & 0.222 & 0.378 & 0.488 \\
\hline \multicolumn{7}{|c|}{ A 2.2 (average slope of $2 \%$ ) } \\
\hline $\mathrm{N}$ & 1304 & 1304 & 1304 & 1755 & 1755 & 1755 \\
\hline Minimum error (m) & 0.000 & 0.000 & 0.000 & 0.000 & 0.000 & 0.000 \\
\hline Maximum error (m) & 0.185 & 0.273 & 0.400 & 0.285 & 0.416 & 0.705 \\
\hline Average error (m) & 0.026 & 0.092 & 0.116 & 0.127 & 0.147 & 0.151 \\
\hline $\mathrm{CV}(\%)$ & 169.2 & 130.4 & 122.4 & 125.1 & 129.2 & 162.9 \\
\hline$\sigma(\mathrm{m})$ & 0.044 & 0.120 & 0.142 & 0.159 & 0.190 & 0.246 \\
\hline $2 \sigma(\mathrm{m})$ & 0.088 & 0.240 & 0.284 & 0.319 & 0.380 & 0.492 \\
\hline
\end{tabular}

$\mathrm{N}$ : Number of sampling points; CV (\%): Coefficient of variation; $\sigma$ : Standard deviation; $2 \sigma: 95 \%$ error probability

Direction shifts of automatic steering tractors were below the accepted limit of $0.10 \mathrm{~m}$. Conversely, those of manual steering increased significantly, being two to three times above the acceptable limit.

Regarding trailers, direction shifts in tractors using automatic steering were above $0.10 \mathrm{~m}$. Yet, errors of both the first and the second trailers remained close in all areas, averaging 1.5 times above the acceptable for the automatic steering and 4.0 times for the manual system.

Both in A2.1 and A2.2, using automatic steering, the frequency curve of both trailers remained very close. Also, these errors stalled quickly, and about $90 \%$ of the path errors were between 0.00 to $0.10 \mathrm{~m}$ for the tractor. In the case of manual steering, this value went to $0.30 \mathrm{~m}$ (Figure 3). 
Area 2.1

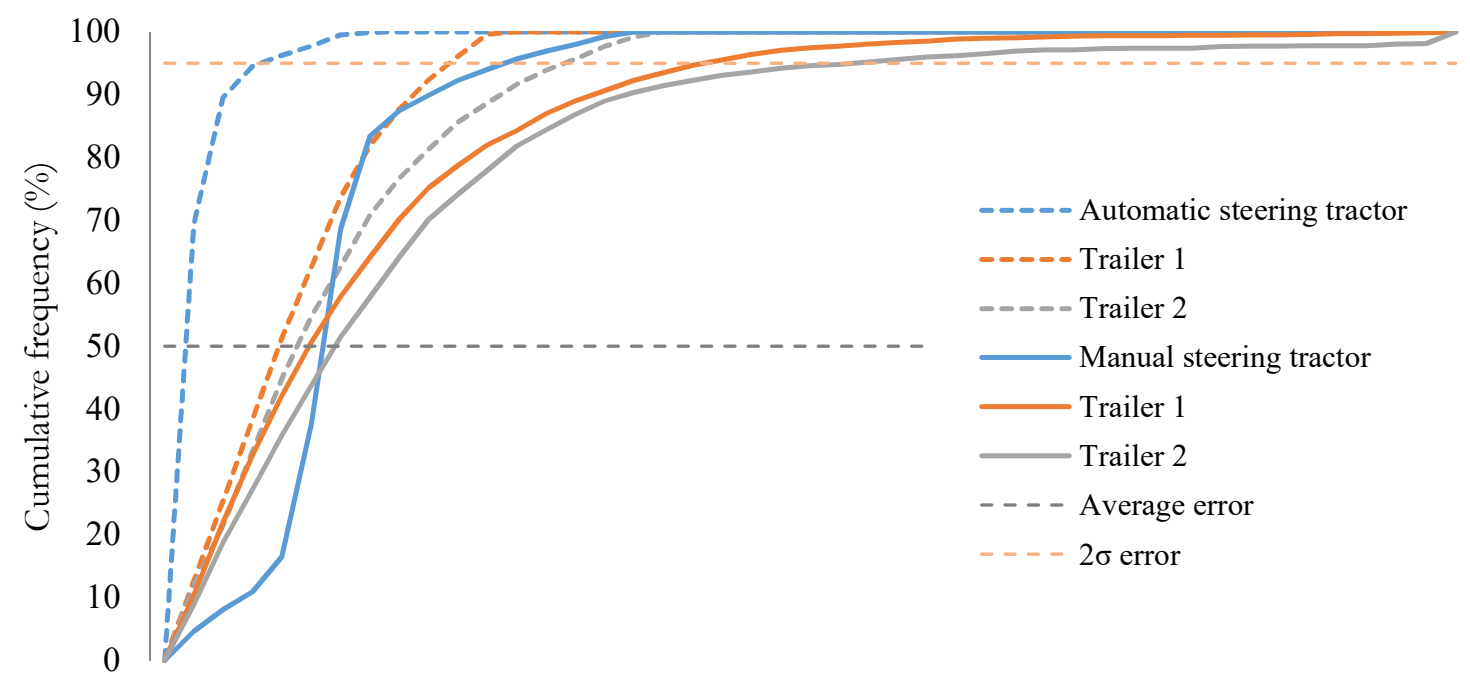

Area 2.2

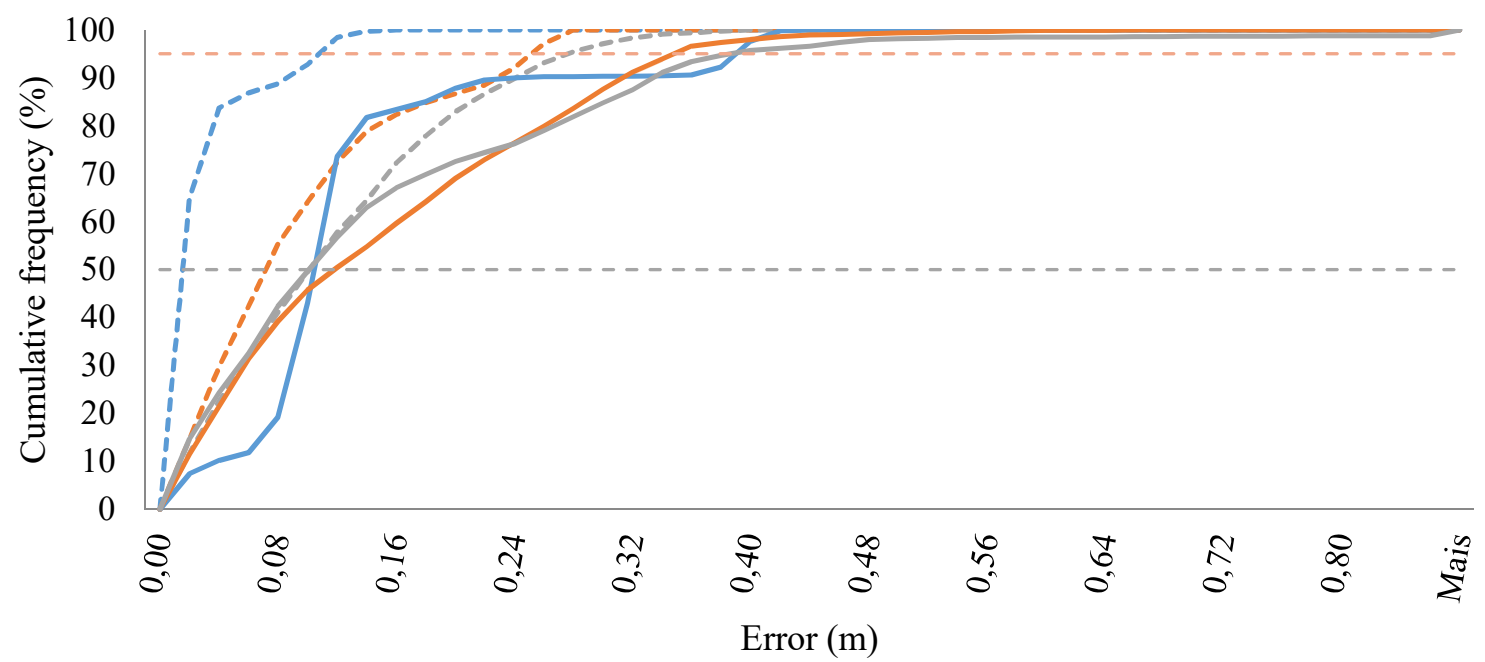

FIGURE 3. Cumulative frequency (probability) of errors per part of the set in little-slope areas, and automatic and manual steering.

In the third experiment (Table 4), with greater cross-sectional slopes, path errors of manual steering tractors were steadily higher than those of automatic steering tractor, reaching $0.36 \mathrm{~m}$ and $0.08 \mathrm{~m}$ respectively (area A3.3). By slightly increasing slope from 7 to $8 \%$ on average (areas A3.2 and A3.3), errors increased by $0.10 \mathrm{~m}$. 
TABLE 4. Pass-to-pass errors of each set part (tractor and transhipment trailers) in areas with greater slope (experiment 3 ) and with automatic and manual steering.

\begin{tabular}{|c|c|c|c|c|c|c|}
\hline \multicolumn{7}{|c|}{ A3.1 (average slope of $5 \%$ ) } \\
\hline & \multicolumn{3}{|c|}{ Automatic steering } & \multicolumn{3}{|c|}{ Manual steering } \\
\hline & Tractor & Trailer 1 & Trailer 2 & Tractor & Trailer 1 & Trailer 2 \\
\hline $\mathrm{N}$ & 523 & 523 & 523 & 503 & 503 & 503 \\
\hline Minimum error (m) & 0.000 & 0.000 & 0.000 & 0.000 & 0.001 & 0.001 \\
\hline Maximum error (m) & 0.154 & 0.249 & 0.537 & 0.320 & 0.899 & 0.980 \\
\hline Average error (m) & 0.022 & 0.058 & 0.094 & 0.090 & 0.113 & 0.164 \\
\hline $\mathrm{CV}(\%)$ & 140.9 & 137.9 & 130.8 & 140.0 & 111.2 & 164.6 \\
\hline$\sigma(\mathrm{m})$ & 0.025 & 0.051 & 0.077 & 0.082 & 0.092 & 0.188 \\
\hline $2 \sigma(\mathrm{m})$ & 0.062 & 0.160 & 0.246 & 0.252 & 0.296 & 0.540 \\
\hline \multicolumn{7}{|c|}{ A3.2 (average slope of 7\%) } \\
\hline $\mathrm{N}$ & 456 & 456 & 456 & 436 & 436 & 436 \\
\hline Minimum error (m) & 0.000 & 0.001 & 0.000 & 0.000 & 0.047 & 0.000 \\
\hline Maximum error (m) & 0.230 & 0.269 & 0.407 & 0.422 & 0.867 & 1.485 \\
\hline Average error (m) & 0.024 & 0.097 & 0.103 & 0.116 & 0.168 & 0.200 \\
\hline $\mathrm{CV}(\%)$ & 133.3 & 121.6 & 132.0 & 118.9 & 99.4 & 138.5 \\
\hline$\sigma(\mathrm{m})$ & 0.029 & 0.070 & 0.085 & 0.080 & 0.083 & 0.178 \\
\hline $2 \sigma(\mathrm{m})$ & 0.064 & 0.236 & 0.272 & 0.276 & 0.334 & 0.555 \\
\hline \multicolumn{7}{|c|}{ A3.3 (average slope of $8 \%$ ) } \\
\hline $\mathrm{N}$ & 1491 & 1491 & 1491 & 1055 & 1055 & 1055 \\
\hline Minimum error (m) & 0.000 & 0.000 & 0.002 & 0.000 & 0.003 & 0.000 \\
\hline Maximum error (m) & 0.240 & 0.481 & 0.575 & 0.347 & 1.287 & 1.460 \\
\hline Average error (m) & 0.023 & 0.098 & 0.147 & 0.146 & 0.229 & 0.243 \\
\hline $\mathrm{CV}(\%)$ & 182.6 & 131.7 & 123.8 & 119.8 & 100.0 & 127.1 \\
\hline$\sigma(\mathrm{m})$ & 0.030 & 0.106 & 0.109 & 0.109 & 0.115 & 0.187 \\
\hline $2 \sigma(\mathrm{m})$ & 0.084 & 0.341 & 0.364 & 0.358 & 0.458 & 0.618 \\
\hline
\end{tabular}

$\mathrm{N}$ : Number of sampling points; CV (\%): Coefficient of variation; $\sigma$ : Standard deviation; $2 \sigma: 95 \%$ error probability

Path errors of trailer wheels were above the acceptable in all studied terrains. Moreover, errors of the third axle in the second trailer are always higher than those in the third axle of the first trailer, indicating a lateral misalignment by inclination (Figure 4). 
Area 3.1

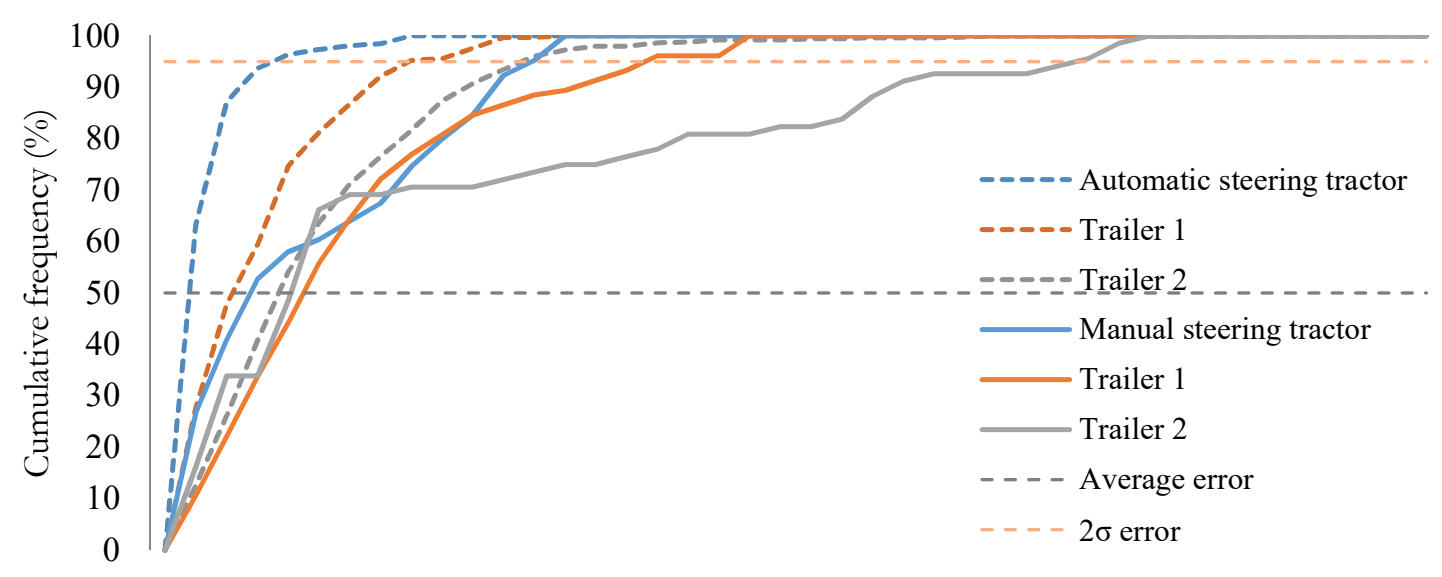

Area 3.2

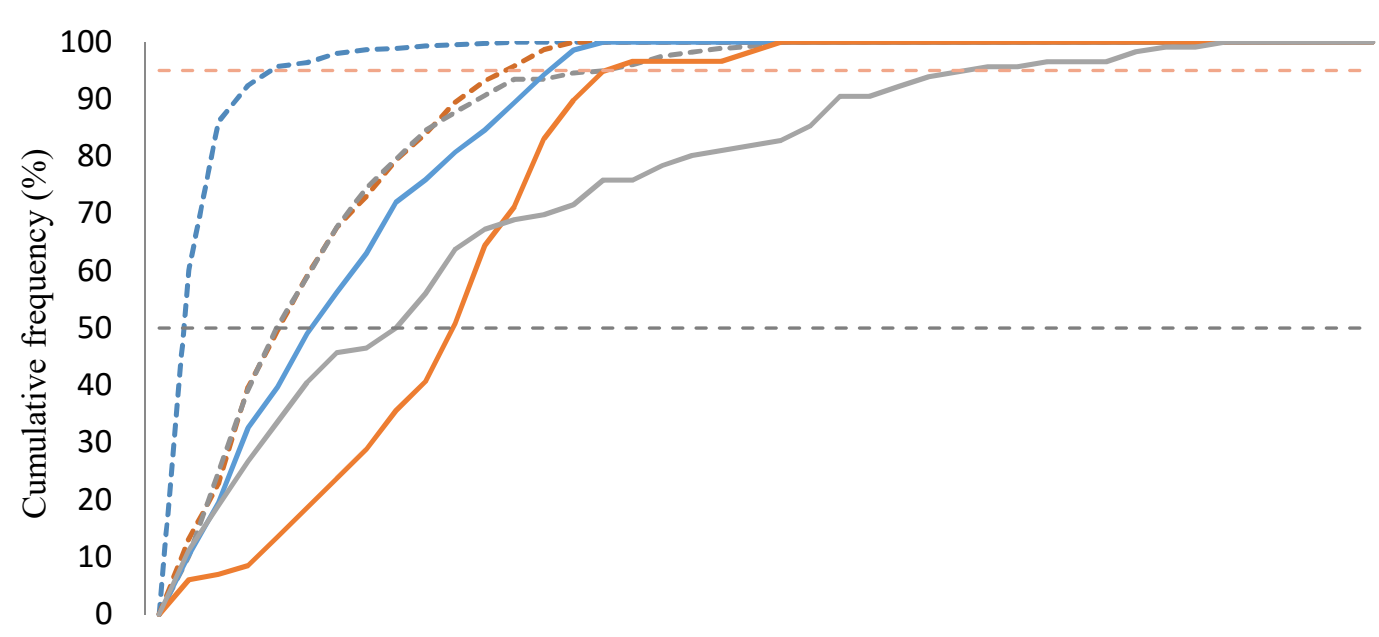

Area 3.3

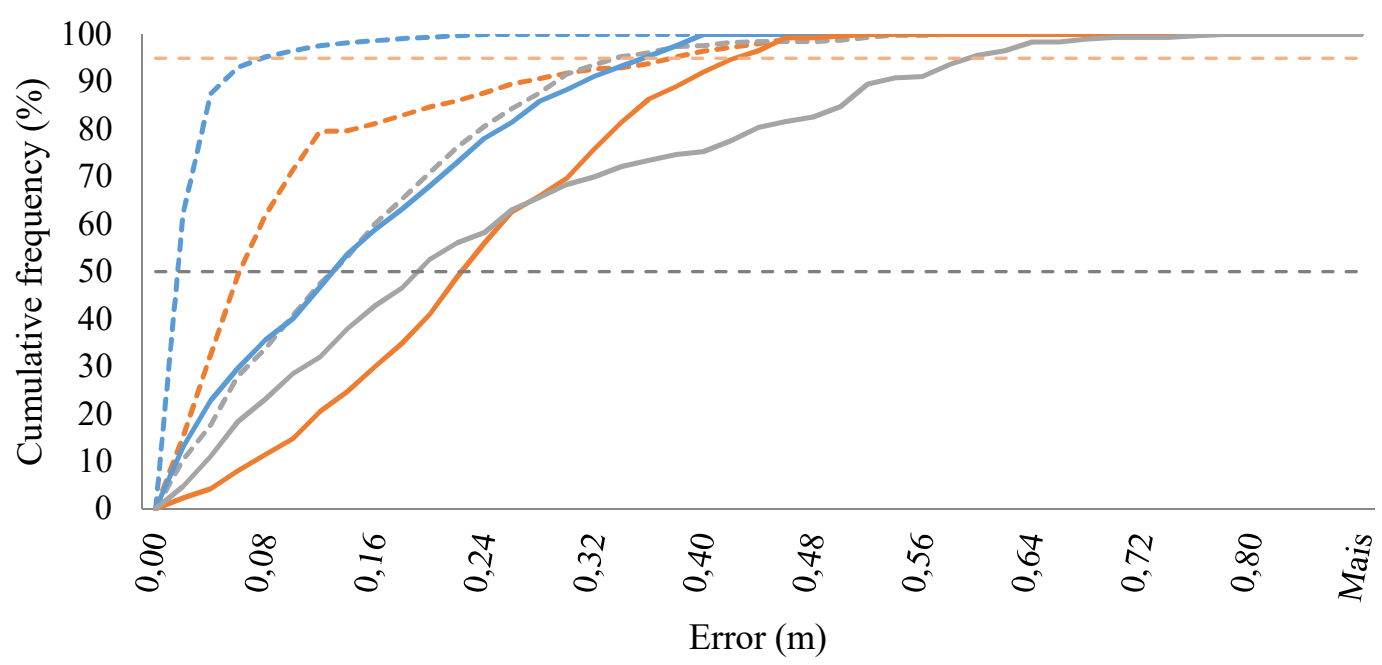

FIGURE 4. Cumulative frequency (probability) of errors for each set part (tractor and transshipment trailer) in areas with average slopes from 5 to $8 \%$, and automatic and manual steering. 
For traffic control, both relief and path type must be considered in pre-programmed routes with automatic steering. In steep-slope terrains and curved paths, another factor would be the trailer path, which tends to have smaller curvature radii when errors increase significantly. Therefore, automatic steering becomes less effective as it does not correct errors inherent to path type of the articulated set.

In smaller cross-slopes, automatic steering was effective since it kept error within the acceptable limit. But, as the lateral slope increased, tractor path errors exceeded the established limit, even with an automatic steering system. Direction shifts were greater in trailers and in paths with a higher lateral slope, where automatic steering, acting only on the tractor, had a reduced effect. Likewise, this was evidenced in curved paths, corroborating the findings of Backman et al. (2010), who observed that, in curved paths, trailers tend to deviate from the tractor's path, which increases with terrain slope.

To minimize path errors of tractor-trailer sets, besides traction vehicle automatic steering, actuators are required in the wheels or the header of trailers. Such solutions have been studied and proposed, as by Thanpattranon et al. (2016), who proposed the use of a sliding drawbar to control the position of the towed vehicle. These authors obtained satisfactory results for path error corrections in tests under controlled conditions but using only one trailer. Likewise, more complex solutions have recently been studied. These are often related development of autonomous vehicles, which require maximum path and maneuver control (Graf Plessen \& Bemporad, 2017; Kayacan et al., 2015).

Several authors have proposed automating the entire set (Backman et al., 2010; Kayacan et al., 2014), based on pre-programmed paths that define route and steering angles for all parts of the set. Nevertheless, specialist literature lacks studies testing more complex conditions, e.g. two towed trailers, or even field studies on side slope effects. Other solutions comprise use of transhipment vehicles mounted on a truck chassis, which are already offered on the market.

\section{CONCLUSIONS}

The proposed method was able to quantify shifts in tractor-trailer set directions, under the evaluated conditions. Misalignment between tractor and trailer were strongly associated with terrain lateral slope and path type (straight or curved). These misalignments were also increasingly affected from one part of the set to the other. Trailer path errors were well above the acceptable limit. Thus, under critical situations, the wheels of the last axle of the second trailer pass over the adjacent crop row, breaking the controlled-traffic concept. Still, complementary solutions to tractor automatic steering must be further sought.

\section{REFERENCES}

Backman J, Oksanen T, Visala A (2010) Nonlinear model predictive trajectory control in tractor-trailer system for parallel steering in agricultural field operations. In: Agricontrol. Kyoto, IFAC.

Belardo GC, Rosa JHM, Magalhães PSG (2015) Colheita mecanizada de cana-de-açúcar: Evolução da colheita mecanizada na cultura de cana-de-açúcar. In: Belardo GC, Cassia MT, Silva RP Processos agrícolas e mecanização da cana-de-açúcar. Jaboticabal, São Paulo, SBEA (1):341-342.

Easterly DR, Adamchuk VI, Kocher MF, Hoy RM (2010) Using a vision sensor system for performance testing of satellite-based tractor auto-steering. Computers and Electronics in Agriculture 72:107-118.

Graf Plessen M, Bemporad A (2017) Reference trajectory planning under constraints and path tracking using linear time-varying model predictive control for agricultural machines. Biosystems Engineering 153:28-41.

Kayacan E, Ramon H, Sayes W (2014) Distributed nonlinear model predictive control of an autonomous tractor-trailer system. Mechatronics, 24:926-933.

Kayacan E, Kayacan E, Ramon H, Saeys W (2015) Learning in centralized nonlinear model predictive control: Application to an autonomous tractor-trailer system. IEEE Transactions on Control Systems Technology 23:197-205.

Molin JP, Povh FP, Paula VR, Salvi JV (2011) Método de avaliação de equipamentos para direcionamento de veículos agrícolas e efeito de sinais de GNSS. Engenharia Agrícola 31(1):121-129. Available:

http://www.scielo.br/pdf/eagri/v31n1/v31n1a12.pdf. Accessed: Jul 20, 2018.

Paula VR, Molin JP (2013) Assessing damage caused by accidental vehicle traffic on sugarcane ratoon. Applied Engineering in Agriculture 29(2):161-169.

Rounsaville J, Dvorak J, Stombaugh T (2016) Methods for calculating relative cross-track error for ASABE/ISO Standard 12188-2 from discrete measurements. Transactions of the ASAE 59(6):1609-1616.

Spekken M, Bruin S de, Molin JP, Sparovek G (2016) Planning machine paths and row crop patterns on steep surfaces to minimize soil erosion. Computers and Electronics in Agriculture. 124:194-210.

Spekken M, Salvi JV, Molin JP (2014) A method to evaluate parallelism for machine logged positions. In: International Conference on Robotics and Associated High-technologies and Equipment for Agriculture and Forestry (RHEA). Madri, Proceedings...

Thanpattranon P, Ahamed T, Takigawa T (2016) Navigation of autonomous tractor for orchards and plantations using a laser range finder: Automatic control of trailer position with tractor. Biosystems Engineering (14):90-103. 